MADD Canada

Faculty of Law, University of Western Ontario, London, Ontario N6A 3K7, Canada

R Solomon

Correspondence to: Professor Solomon rsolomon@uwo.ca

\title{
The tooth fairy, Santa Claus, and the hard core drinking driver
}

\author{
E Chamberlain, R Solomon
}

In recent years, the alcohol industry ${ }^{1-5}$ and certain traffic safety organizations ${ }^{6-9}$ have tried to draw a sharp distinction between so-called "social drinkers" and "hard core drinking drivers". We are led to believe that great progress has been made among social drinkers over the last 20 years, and that this extremely large group invariably drinks "moderately" or "responsibly". In contrast, little progress has been made among the tiny fraction of drivers who make up the hard core drinking driver population. We are urged to "crack down" on this dangerous minority with tougher penalties, particularly for repeat offenders. ${ }^{9}$ Broader enforcement measures and lower criminal blood alcohol concentration (BAC) limits are to be avoided, as they would unnecessarily alienate social drinkers.

The hard core and social drinker rhetoric creates a convenient scapegoat for Canada's and, no doubt, other countries' impaired driving problems. By blaming hard core drinking drivers, proponents of these stereotypes allow mainstream "social drinkers" to separate themselves from the impaired driving issue, without ever having to critically assess their own drinking and driving habits. For example, in a 1999 article, the President of the Brewers Association of Canada recommended that legislative measures be focused on the "small minority of drivers" who are the "real cause of the problem". ${ }^{1}$ He suggested that "great strides" have been made in reducing impaired driving among the general population, and that "hard core" offenders are the last remaining bulwark of irresponsible drinking and driving habits. The President describes this small minority as "repeat offenders, [who] often continue to drive with a suspended license, and remain indifferent to societal pressures to reform".

This mischaracterization of the impaired driving problem limits the reform agenda. For instance, Canada's federal government recently ignored calls for sweeping reforms to the impaired driving law in its 1999 and 2000 Criminal Code amendments. ${ }^{11}{ }^{11}$ The recommendations to strengthen and streamline the enforcement, processing, and prosecution of impaired driving offences were ignored largely without comment. These measures included proposals to: authorize the use of passive alcohol sensors and field sobriety testing, expand the grounds for breath and blood testing, facilitate the introduction of mobile evidentiary breath testing, and eliminate spurious defences. Unfortunately, the government focused on measures targeting "the relatively small group of "hard core' drinking drivers", and "protect[ing] the public from repeat offenders". ${ }^{12}$

The government also rejected the proposal to lower the Criminal Code BAC limit from $0.08 \%$ to $0.05 \%$, because there was a "lack of consensus" over whether it "would achieve greater safety". ${ }^{12}$ This is in spite of the substantial and consistent body of research indicating that: key driving related skills are significantly impaired by relatively small amounts of alcohol ${ }^{13-15}$; drivers with "low" or "moderate" BACs have dramatically increased risks of crash relative to their sober counterparts ${ }^{16-18}$; and jurisdictions that have introduced $0.05 \%$ BAC laws or otherwise lowered their BAC limits have generally shown reductions in alcohol related crashes, injuries, and deaths. ${ }^{19-21}$ The $0.05 \%$ proposal was also condemned because it might "criminalize behaviour that is otherwise perceived as commonplace", ${ }^{22}$ and thereby "result in a loss of public support" for the current law. ${ }^{12}$

Rather than introducing comprehensive reforms, the Canadian government enacted politically easy amendments, focusing almost exclusively on increasing the minimum and maximum penalties for the various offences. When introducing the new penalties, federal Justice Minister McLellan declared that, "our criminal law must send a strong signal that impaired driving will not be tolerated". ${ }^{23}$ Thus, the amendments allowed the government to publicly posture itself as taking a tough stand on impaired driving, in an attempt to garner positive media attention without alienating the alcohol industry. While we do not necessarily oppose increased penalties for impaired drivers, they should not be viewed as a substitute for broader reforms.

Advocates of the hard core stereotype have also attempted to hinder substantive reforms in the United States. In 1999, the alcohol industry temporarily thwarted the federal government's initiative to tie highway funding to a state's implementation of a $0.08 \%$ BAC limit ${ }^{\star}$. The National Licensed Beverage Association (NLBA) argued that "lowering the BAC limit diverts scarce law enforcement resources away from the real enemy, the hard-core, high-BAC drinking driver". ${ }^{3}$ The NLBA also mobilized

* The $0.08 \%$ funding initiative was eventually made law in October 2000. 
an intense grassroots lobby movement to fight the proposed amendment. As an alternative, the NLBA suggested "measures that are truly effective, whether it's mandatory jail sentences, license revocation, or tougher penalties for repeat offenders".

The movement to denounce and crack down on "hard core" offenders has received widespread support from the alcohol industry. For example, The Century Council's National Hardcore Drunk Driver Project, funded by "America's leading distillers", describes hard core offenders as "irresponsible, reckless and abnormal in their drinking patterns", ${ }^{2}$ while the Beer Institute supports "increasingly tough punishments... for those convicted of multiple drunk driving offenses" ${ }^{24}$ Similarly, the American Beverage Institute suggests that "alcohol abusers.... should be incapacitated like any public menace-with substantial prison terms". ${ }^{5}$

These attempts to lay blame on stereotypical "hard core" offenders and discount the impaired driving problem are analogous to the situation with HIV in the early 1980s. Initially, HIV was characterized as a problem for homosexuals, prostitutes, and intravenous drug users, but not the general public. HIV was misleadingly linked to marginalized groups, rather than the high risk behaviours that spread the virus. In the same way, it is disingenuous to attribute impaired driving to only hard core drinking drivers. Rather, the focus should be on the high risk behaviours that generate alcohol related crashes, injuries, and deaths.

Part of the hard core stereotype's allure can be attributed to its malleable terminology. The term "hard core" drinking driver is often used to describe three different, albeit overlapping, groups of drivers. The term is sometimes used to refer to those who routinely or "persistently" drive after drinking. ${ }^{85-27}$ Other times it refers to repeat impaired driving offenders. ${ }^{6828-30}$ However, a "hard core" drinking driver appears to be most often defined as any driver with a high BAC, typically above $0.15 \% . .^{69^{25-27}}$ Nevertheless, a brief survey of the literature indicates that such high risk behaviour is not limited to a tiny fraction of the population, and is far more prevalent than the promoters of the "hard core" stereotype would lead us to believe.

In particular, the dichotomy between "hard core" and "social drinkers" ignores those people who usually drink moderately, but occasionally drink to excess. These people are not alcoholics, and would not generally be viewed as "hard core" drinkers. For example, a significant percentage of young people, especially males, go through a period of episodic heavy drinking. A recent Canadian survey reported that $13 \%$ of young drinkers admitted to engaging in binge drinking (five or more drinks in a sitting) 52 times a year. ${ }^{31}$ Similarly, two thirds of the undergraduate students who participated in the 1998 Canadian Campus Survey admitted to having five or more drinks in a sitting in the two or three months before the survey, ${ }^{32}$ and one third reported having eight or more drinks in a sitting during that period. Moreover, those undergraduate students who admitted to consuming five or more drinks in a sitting did so an average of 13.4 times during the past year.

Not surprisingly, this pattern of binge drinking among young adults is also evident outside of Canada. In a 2000 study, the Harvard School of Public Health found that $23 \%$ of American college students were "frequent binge drinkers", that is, they had engaged in binge drinking three or more times in the two weeks before the survey. ${ }^{33}$ Furthermore, Australian statistics indicate that $51 \%$ of males aged 18-24 consume at least nine alcoholic drinks per drinking occasion, and are at high risk of short term health problemst. ${ }^{34}$ However, these young people probably see themselves, and are likely seen by others, as simply liking a good party, not as "hard core" drinkers.

Furthermore, despite whatever progress may have been made among so-called "social drinkers", a sizeable percentage of Canada's population continues to drink and drive. In the 1999 National Opinion Poll on Drinking and Driving, $19.3 \%$ of licensed drivers said that they had recently driven within two hours of drinking. ${ }^{35}$ In the authors' words, "when applied to the entire population of licensed drivers, it shows that over four million Canadians admit to driving after drinking". Moreover, 54\% of those who admit to driving within two hours of drinking do so at least three times a month. Finally, based on the survey results, the authors estimated that 2.3 million Canadians have driven when they thought they were over the legal limit. ${ }^{35}$

Again, it is not surprising that these drinking and driving patterns also exist outside of Canada. In New Zealand, it was estimated that an average of 54400 trips are made every day by drivers within one hour of drinking. ${ }^{36}$ Similarly, a 1999 survey conducted by the National Highway Traffic Safety Administration (NHTSA) reported that $24 \%$ of Americans aged 16 and over admit to driving within two hours of drinking. ${ }^{37}$ The study estimated that 811 million to 1.1 billion impaired driving trips occurred in the United States in 1997, with "problem drinkers" accounting for roughly $40 \%$ of the total. This means that more stereotypical "social drinkers" made the remaining $60 \%$ of impaired driving trips. ${ }^{37}$ Clearly, it is misleading to attribute the impaired driving problem to what one commentator described as the "dangerous $1 \%$ " of hard core drinking drivers. 9

Granted, there is a small number of people who frequently drive with high BACs, and they are, no doubt, dramatically over-represented in alcohol related crashes. Nevertheless, given the sheer number of people who occasionally binge drink and drive, this much larger group is probably responsible for most of the alcohol

†It should be noted that a "standard drink" in Australia contains $10 \mathrm{~g}$ of ethyl alcohol, while a "standard drink" in the United States contains $13.6 \mathrm{~g}$ of ethyl alcohol. Thus, nine standard drinks in Australia contain approximately the same amount of alcohol as 6.5 standard drinks in the United States. Standard drinks in Canada contain roughly $15 \mathrm{~g}$ of ethyl alcohol. 
related crashes, injuries, and deaths. Indeed, the research indicates that occasional binge drinkers are at a much higher relative risk of crash per trip than frequent drinking drivers with the same BACs. For example, an American report indicated that, at the relatively modest BAC of $0.06 \%$, the risk of crash relative to their sober counterparts increases nearly $700 \%$ for those who drink on an annual basis, 425 for those who drink monthly, and 50 for those who drink daily. ${ }^{38}$ Presumably, the relative risk for infrequent drinkers is even more disproportionate at the high BAC levels typically associated with traffic crashes.

Thus, contrary to the stereotype, the research establishes that a significant number of so-called "social drinkers" occasionally drive with high BACs. Moreover, when they do so, they are at an extremely high risk of crash. It is inappropriate to ignore this significant subset of "social drinkers" in our attempts to find a convenient scapegoat for the impaired driving problem. We would be better served to discard the value laden labels and focus on the high risk drinking and driving behaviour.

As indicated, the term "hard core" drinking driver is also used to refer to repeat impaired driving offenders. It is suggested that both enforcement and legislative attention must be focused on these individuals. However, contrary to the view put forth by the alcohol industry and adopted by various governments, "hard core" or repeat offenders appear to be responsible for a relatively small percentage of alcohol related crashes.

A recent comprehensive review article published by the NHTSA indicates that repeat offenders play a relatively small role in the impaired driving crash problem. ${ }^{39}$ NHTSA reported that convicted impaired driving offenders are over-represented in crashes by a factor of only 1.4. Moreover, only $2.2 \%$ of all fatal crashes involve a driver who has been convicted of impaired driving in the past three years. Even when only alcohol related fatal crashes are considered, the involvement of convicted impaired drivers rises to only $8 \%$. The NHTSA study concludes, "even if all alcohol-related fatal crashes involving repeat offenders were eliminated, at least $90 \%$ of all fatal crashes would still remain". ${ }^{39}$ However, this study used a very short "look back" period in defining the term "repeat offender". Presumably, the role of repeat offenders would have been greater if a longer period had been used. Nevertheless, the NHTSA study suggests

$¥$ Indeed, Canadian statistics indicate that those aged 15-24 have double the rate of crash deaths, and nearly double the rate of crash injuries, as those aged 35-54. Males accounted for $87 \%$ of the fatally injured and $89 \%$ of the seriously injured drivers. In addition, more than half of the fatally injured $20-24$ year olds and $40 \%$ of the fatally injured 15-19 year olds had been drinking.

\# The Traffic Injury Research Foundation estimated in 1997 that 1680 people die in Canada each year as a result of alcohol related crashes. In contrast, Statistics Canada figures indicate that there were 536 homicides in 1999, including all murder, manslaughter, and infanticide cases.

\section{Key points}

- The recent focus on "hard core" drinking drivers marginalizes the impaired driving problem and inhibits substantive legislative reform.

- A sizeable percentage of so-called "social drinkers" engage in binge drinking behaviour that is sufficient to produce BACs in the typical "hard core" range.

- Nearly $20 \%$ of licensed drivers in Canada continue to drink and drive.

- Infrequent drinkers have a much higher relative risk of crash than heavy drinkers with the same BACs.

- It would be prudent to discard the value laden labels of "social drinkers" and "hard core" drinking drivers and focus instead on high risk drinking behaviours.

that more comprehensive measures are required to reduce impaired driving, and undermines the simplistic view that a crackdown on repeat offenders would solve the problem.

The alcohol industry, governments, and some traffic safety experts continue to claim that there is little more we can do to address impaired driving other than target hard core drinking drivers and toughen sanctions. Although we support improved prosecutorial and sentencing practices, we wholly disagree with the narrow focus on hard core drinking drivers. The "hard core" stereotype mischaracterizes the impaired driving problem, and ignores a major segment of the population that occasionally drinks immoderately and is responsible for a substantial percentage of impaired driving crashes, injuries, and deaths. In particular, it ignores the problem of episodic heavy drinking among young males, who continue to be dramatically over-represented in crash statisticsł. Not surprisingly, this same constituency is the prime target of almost all alcohol marketing initiatives.

In summary, the myth of the hard core drinking driver detracts attention from more comprehensive approaches that are essential to reducing impaired driving among all segments of the population. Governments are able to portray themselves as taking a hard line by steadily increasing the penalties for convicted offenders, while ignoring more substantive reforms that research indicates will save lives. Unfortunately, until such comprehensive reforms are introduced, impaired driving will remain Canada's leading criminal cause of death, claiming more than three times as many lives per year as all homicides combined\#.

Robert Solomon is a Professor of Law at the University of Western Ontario and the National Director of Legal Policy for Mothers Against Drunk Driving (MADD) Canada. Erika Chamberlain, LL B 2001, is a legal research associate for
MADD Canada. The authors wish to thank MADD Canada for its financial support in preparing this article.

1 Morrison S. Promoting responsible consumption. On Tap 1999;13:1.

2 Century Council. The national hardcore drunk driver project. Wentury Council. The national hardcore

3 National Licensed Beverage Association. NLBA grassroots action stops .08 BAC amendment (news release). Alexandria, VA: NLBA, 28 September 1999. 
4 Latham WR III. A critical review of two NHTSA studies. Washington, DC: American Beverage Institute, 1997.

5 American Beverage Institute. The .08 debate: what's the harm? Washington, DC: American Beverage Institute, 1997.

6 Donelson AC. The alcohol-crash problem and its persistence: the need to deal effectively with the hard core of drinking drivers. 34th International Institute on the Prevention and Treatment of Alcoholism. Pontault-Combault, France, 8 June 1989.

7 Simpson HM. The repeat offender: future directions for impaired driving programs and policies. Countermeasures conference. Toronto, Ontario, 22 February 1993.

8 Beirness DJ, Mayhew DR, Simpson HM. DWI repeat offenders: a review and synthesis of the literature. Ottawa: Health Canada, 1997.

9 Therien E. One for the road [editorial]. Globe and Mail 18 January 2001.

10 An Act to amend the Criminal Code (impaired driving and related matters), Statutes of Canada 1999, c32

11 An Act to amend the Criminal Code (impaired driving causing death and other matters), Statutes of Canada 2000, c25.

12 Standing Committee on Justice and Human Rights. Toward eliminating impaired driving. Ottawa: Publications Service,

13 Moskowitz H, Fiorentino D. A review of the literature on the effects of low doses of alcohol on driving related skills. Washing ton, DC: National Highway Traffic Safety Administration, 2000.

14 Moskowitz H, Burns M, Fiorentino D, et al. Driver characteristics and impairment at various BACs. Washington, DC: National Highway Traffic Safety Administration, 2000.

15 Howat P, Sleet D, Smith I. Alcohol and driving: is the $0.05 \%$ blood alcohol concentration limit justified? Drug Alcohol Rev 1991;10:151-66.

16 Borkenstein RF, Crowther RF, Shumate RP, et al. The role of the drinking driver in traffic accidents. Bloomington: Indiana University Department of Police Administration, 1964.

17 McLean AJ, Holubowycz OT, Sandow BL. Alcohol and crashes: identification of relevant factors in this association. crashes: identification of relevant factors in this

18 Perrine MW, Waller JA, Harris LS. Alcohol and highway safety: behavioural and medical aspects. Washington, DC: Department of Transportation, 1971.

19 Mercier-Guyon C. Lowering the BAC limit to 0.05: results of the French experience. Transportation Research Board 77th Annual Meeting. Washington, DC, 11-15 January 1998.

20 Norström T, Laurell H. Effects of lowering the legal BAC-limit in Sweden. In: Mercier-Guyon C, ed. Alcohol, drugs and traffic safety, T-'97. Annecy: Centre d'études et de recherche en médecine du trafic, 1997: 87-94.

21 Henstridge J, Homel R, MacKay P. The long-term effects of random breath testing in four Australian states: a time series analysis. Canberra: Federal Office of Road Safety, 1997.
22 Simpson HM, Mayhew DR, Beirness DJ. Recommendations for improving the impact of federal impaired driving laws. Submission to the Standing Committee on Fustice and Human Rights. Ottawa: Traffic Injury Research Foundation, 1999.

23 Canada, Department of Justice. Government to strengthen impaired driving law (news release). 7 June 1999.

24 Beer Institute. High risk drivers are over-represented in crashes (news release). 27 July 2000.

25 Simpson HM, Mayhew DR, Beirness DJ. Dealing with the hard core drinking driver. Ottawa: Traffic Injury Research Foundation, 1996.

26 Sweedler BM. Strategies for dealing with the persistent drinking driver. Washington, DC: National Transportation Safety Board, 1997.

27 Bailey JPM, Bailey ML. Hard-core drinking drivers in New Zealand. Whitby, NZ: Bailey Partnership Ltd, 2000.

28 Brewer RD, Morris PD, Cole TB, et al. The risk of dying in alcohol-related automobile crashes among habitual drunk drivers. N Engl f Med 1994;331:513-22.

29 Siegal HA, Falck RS, Carson RG, et al. The hardcore drunk driving offender. Dayton: Centre for Interventions, Treatment and Addictions Research, 2000.

30 Wieczorek WF, Callahan CP, Nochajski TH. An empirical typology of persistent drinking drivers. Buffalo: Center for Health and Social Research at Buffalo State College, 2000.

31 Statistics Canada. Statistical report on the health of Canadians, 1996-1997. Ottawa: Statistics Canada, 1999.

32 Gliksman L, Demers A, Adlaf EM, et al. Canadian campus survey 1998. Toronto: Centre for Addiction and Mental Health, 2000

33 Wechsler H, Lee JE, Kuo M, et al. College binge drinking in the 1990s: a continuing problem. Results of the Harvard School of Public Health 1999 College Alcohol Study. Boston: Harvard School of Public Health, 2000.

34 Heale P, Stockwell T, Dietze P, et al. Patterns of alcohol consumption in Australia, 1998. Perth: National Drug Strategy, 2000.

35 Simpson HM, Beirness DJ, Mayhew DR. National opinion poll on drinking and driving. Ottawa: Traffic Injury Research Foundation, 1999

36 New Zealand Travel Survey 1997/98. Wellington, NZ: Land Transport Safety Authority, 1999.

37 Royal D. Volume I: Findings - National survey of drinking and driving behaviour. Washington, DC: Gallup Organization and National Highway Traffic Safety Administration, 2000.

38 Snyder MB. Driving under the influence: a report to congress on alcohol limits. Washington, DC: National Highway Traffic Safety Administration, 1992.

39 Jones RK, Lacey JH. State of knowledge of alcohol-impaired driving: research on repeat DWI offenders. Washington, DC: National Highway Traffic Safety Administration, 2000. 